\title{
AS EXPRESSÕES DE PEDIDO EM JAPONÊS DOS NISSEIS BRASILEIROS NO BRASIL - ANÁLISE COM A TEORIA DE MOVE, COM FOCO EM DUAS SITUAÇÕES ${ }^{1,2}$ THE EXPRESSIONS FOR MAKING REQUESTS OF BRAZILIAN NISEIS IN BRAZIL - ANALYZE WITH THE THEORY OF MOVE, FOCUSED ON TWO SITUATIONS
}

\author{
Douglas Kasunobu Ono ${ }^{3}$ \\ (Kyoto University of Foreign Studies) \\ Junko Ota ${ }^{4}$ \\ (Universidade de São Paulo)
}

Resumo: Para identificarmos as características do modo como os nisseis brasileiros residentes no Brasil se comunicam em japonês, neste presente trabalho escolhemos como tema da pesquisa o uso das expressões de pedidos. Quando não usados adequadamente, os pedidos podem provocar atritos na interação com falante nativo de japonês, por causa da diferença na percepção cultural e social. Para realizarmos uma pesquisa a partir de conceitos pragmáticos, fizemos a coleta de dados dos nisseis brasileiros através das respostas escritas em questionários, em que se estabeleceram situações com graus variados de ônus imposto ao interlocutor. Os resultados obtidos pelos questionários aplicados aos nisseis brasileiros foram comparados com o modelo apresentado por Kabaya (1993), que, em sua pesquisa, apresentou modelos de estratégias de como são realizados os pedidos em japonês no Japão. A comparação mostrou que os informantes usam estratégias

1 Artigo submetido em 28.1.2020 e aceite em 14.01.2021

2 Este trabalho tem como base o capítulo 4 da dissertação de mestrado do primeiro autor, defendido em 2014, no Programa de Língua, Literatura e Cultura Japonesa, da Faculdade de Filosofia, Letras e Ciências Humanas da Universidade de São Paulo.

3 Doutorando do Programa de Línguas e Culturas Estrangeiras da Kyoto University of Foreign Studies e Mestre pelo Programa de Língua, Literatura e Cultura Japonesa da Universidade de São Paulo; e-mail douglas_scorpions@hotmail.com (ORCID iD: https://orcid.org/0000-0001-5489-1644).

4 Docente do curso de Língua e Literatura Japonesa do Departamento de Letras Orientais da Faculdade de Filosofia, Letras e Ciências Humanas da Universidade de São Paulo, São Paulo, Brasil. Doutora em Linguística pela Universidade de São Paulo; junkoota@usp.br (ORCID iD: https://orcid. org/0000-0002-0392-4722). 
aceitáveis para pedidos simples, mas não exatamente apropriadas; e para pedidos complexos, fazem uso de estratégias não satisfatórias.

Palavras-chave: Expressões de pedido; Estratégia; Unidade de função enunciativa; Move; Língua japonesa dos nisseis brasileiros

Abstract: In this article we chose the use of expressions for making requests as our research theme. The aim was to identify and characterize the way Brazilian niseis living in Brazil communicate in Japanese. When used incorrectly, request expressions can cause friction in the interaction between people of different cultural and social backgrounds. Data was collected through questionnaires filled out by Brazilian niseis, identifying various situations with different degrees of burden imposed on the interlocutor. The results obtained from this were then compared to the models of strategies for how requests are worded in Japanese, in Japan, as presented by Kabaya (1993). The comparison showed that the informants use acceptable strategies for simple requests and make use of unsatisfactory strategies for complex requests.

Keywords: Request expressions; Strategy; Enunciative function unit; Move; Japanese language of Brazilian niseis

\section{INTRODUÇÃO}

Qualquer pessoa, independente de sua língua, deve ter conhecimento gramatical da língua, mesmo que de forma intuitiva, e o domínio das variações pragmáticas para ter sucesso na comunicação com o outro. Quem se comunica em língua japonesa terá que fazer ainda uso das variadas estratégias de comunicação para não ameaçar a si mesmo, a própria face, ou ameaçar a face do interlocutor. É uma das características da língua japonesa, que tem uma forte presença de elementos linguísticos que levam em conta a presença do interlocutor, resultando nas gradações de respeito e polidez com uma grande sutileza. A atenção se desdobra, sobretudo quando se quer fazer ao interlocutor um pedido.

Por este motivo, propomos analisar a forma como os brasileiros da segunda geração dos descendentes japoneses (a seguir, serão referidos apenas como 'nisseis') se expressam, com o objetivo de estudar quais são as estratégias utilizadas pelos informantes ao realizar um pedido e ao mesmo tempo observar se o desempenho dos informantes é satisfatório comparado com a comunicação dos japoneses no Japão e identificar os fatores sociais que influenciam na realização de um pedido.

Neste presente trabalho, escolhemos verificar as formas de fazer pedidos em japonês dos nisseis brasileiros, uma vez que, ao realizá-los, o locutor tenta reduzir o ônus gerado na situação, sempre utilizando expressões, atento às circunstâncias de enunciação do pedido, idade, posição social do interlocutor e o grau de dificuldade em satisfazer o pedido, com a intenção de fazer com que o interlocutor realize o que lhe será pedido. Como existem diferenças sociais e culturais entre japoneses do Japão e nisseis do Brasil, supomos que os procedimentos de pedido realizados por ambos possuam algumas características diferentes. 


\section{FUNDAMENTAÇÃO TEÓRICA}

Nesta pesquisa, abordaremos as expressões de pedidos faladas pelos nisseis, o que torna essencial vermos teorias como de Searle (1981), Kumatoridani (1995) e Kabaya (1993), para sabermos as principais características das expressões de pedido e os tipos de situações em que são realizadas.

Segundo Searle (1981), que se baseia na teoria de ato de fala de Austin (1962), as pessoas não usam a linguagem apenas para fazerem declarações sobre o mundo, mas também para executar ações específicas que possuem forças específicas. Um ato de fala, para ser considerado como uma expressão de pedido, deve satisfazer as seguintes condições:

\section{Quadro 1- Condições essenciais para se realizar um pedido}

\begin{tabular}{|l|l|}
\hline Conteúdo proposicional & Um ato futuro A, a ser realizado pelo interlocutor O. \\
\hline Preparatória & $\begin{array}{l}\text { O interlocutor O está em condições de realizar o ato A. O locutor F } \\
\text { acredita que o interlocutor O esteja em condições de realizar o ato A. } \\
\text { Não é óbvio nem para F nem para O que O realizará A no } \\
\text { decurso normal dos acontecimentos, por deliberação própria. }\end{array}$ \\
\hline Sinceridade & F quer que O faça A. \\
\hline Essencial & Vale como uma tentativa de conseguir que O faça A. \\
\hline
\end{tabular}

Searle (ibidem) também classifica o pedido como um ato ilocucional diretivo, que são tentativas do locutor de levar o interlocutor a fazer algo. Os atos ilocucionais diretivos podem ser divididos em dois tipos:

a. Diretos: são atos em que o locutor emite um enunciado e quer significar exatamente o que diz, e faz com que o interlocutor atenda a intenção do locutor. Exemplo: "Passe o sal".

b. Indiretos: são atos em que o locutor comunica ao interlocutor mais do que uma sentença realmente diz, por meio da informação de base linguística e não linguística que compartilham e a capacidade de racionalidade e inferência que teria o interlocutor para atender o ato. Exemplo: "Você pode alcançar o sal?"

Para Searle (ibidem), nos atos ilocucionais diretivos indiretos, a polidez é a principal motivação. No exemplo acima, o uso de "Você pode...?" é polido, pelo fato de o locutor não pressupor conhecer as capacidades do interlocutor e dar a opção de uma recusa ao interlocutor.

Kumatoridani (1995) explica sobre as formas indiretas de realizar pedidos em japonês, de acordo com a teoria dos atos da fala de Searle (ibidem), descrita acima, ao mostrar exemplos de pedidos indiretos, como as seguintes expressões que são consideradas como pedidos indiretos por satisfazerem a condição de sinceridade: 
1) Kore o shite hoshiinda kedo.

Gostaria que fizesse isso, mas (tudo bem?).

No caso mencionado acima, para a expressão ser considerada como pedido indireto, há a necessidade do uso de "noda ou nda (ênfase) + kedo ("mas")" no final da sentença, podendo implicitamente levar à pergunta se pode ser assim, que é essencial para essa expressão não se tornar uma simples manifestação de desejo da parte do locutor.

Segundo Kumatoridani (ibidem), a expressão do exemplo 2 é considerada como pedido indireto, por satisfazer a condição preparatória:

\section{2) Kore ashita made ni dekiru kana?}

Será que você consegue fazer isto até amanhã?

No exemplo 3, Kumatoridani (ibidem) destaca que, em expressões de pedido da língua japonesa, há uma peculiaridade na ausência da palavra com força ilocucional, em que estão omitidos os verbos auxiliares "kudasai" (Faça-me ou por favor), "moraitai" (quero que faça), "hoshii" (quero), que indicam o conteúdo proposicional do ato:

3) Chotto matte (kudasai).

Espere um pouco.

vHá também expressões que são difíceis de relacionar com as condições para realizar expressões de pedido, levantadas por Searle, como:

4) Kono heya mushiatsui desu ne.

Esta sala está abafada, não?

No exemplo 4, acima, é possível entender que o locutor está querendo fazer um pedido indireto, como se dissesse "Mado o akete kudasai"(Abra a janela). De acordo com Kumatoridani (ibidem), nesta situação, não há possibilidade de relacionar nenhuma condição para a realização do pedido com o enunciado. Essa expressão deve ser considerada apenas como uma forma indireta de pedido, por conta da situação em que os participantes do evento comunicativo.

Kabaya (1993) cita que é muito importante o locutor considerar a sua distância e a diferença hierárquica com o interlocutor, e o conteúdo da conversa, ao utilizar algum tipo de estratégia no momento de fazer um pedido. Por isso, classificou as situações e o conteúdo em níveis para poder analisar as estratégias utilizadas. Primeiramente, foram estabelecidos quatro níveis para o interlocutor, que aumentam de acordo com o distanciamento e a hierarquia existente entre os participantes da conversa: 


\section{Quadro 2- Níveis dos interlocutores conforme a relação social com os locutores}

\begin{tabular}{|c|l|}
\hline Níveis & Exemplos de interlocutores \\
\hline-1 & Amigo íntimo da mesma idade; um membro da família \\
\hline 0 & Pessoa não muito íntima da mesma idade; alguém que encontrou pela primeira vez \\
\hline 1 & Professor ou chefe com idade próxima \\
\hline 2 & Professor ou chefe mais velho \\
\hline
\end{tabular}

Fonte: baseado em Kabaya (ibidem)

Em segundo plano, o conteúdo do pedido também foi classificado em quatro níveis, aumentando à medida em que o ônus proporcionado ao interlocutor se torna maior:

\section{Quadro 3 - Níveis dos conteúdos conforme a posição espacial e temporal dos integrantes de uma conversa}

\begin{tabular}{|c|l|}
\hline Níveis & Exemplos de conteúdo \\
\hline-1 & $\begin{array}{l}\text { Perguntar o local da plataforma para um funcionário de uma estação de trem. } \\
\text { Perguntar para a professora de japonês como se lê um kanji. }\end{array}$ \\
\hline 0 & $\begin{array}{l}\text { Pedir para o funcionário de uma estação procurar um objeto perdido no trem. } \\
\text { Pedir para a professora de japonês corrigir uma carta. }\end{array}$ \\
\hline 1 & $\begin{array}{l}\text { Pedir para o garçom trocar dinheiro. } \\
\text { Pedir para a professora um livro emprestado. }\end{array}$ \\
\hline 2 & $\begin{array}{l}\text { Pedir dinheiro emprestado. } \\
\text { Pedir para alguém ser fiador de imóvel. }\end{array}$ \\
\hline
\end{tabular}

Fonte: baseado em Kabaya (ibidem)

Finalmente, os níveis dos interlocutores e dos conteúdos são somados, resultando na formação de sete graus de situações de pedidos, em que o locutor utilizará diferentes estratégias de acordo com o ônus que a situação suscita ao interlocutor. Kabaya (ibidem) apresentou modelos de conjuntos de funções enunciativas, que, de acordo com Foucault (1969), é a correlação entre o que se diz e as ações colocadas em prática ou seu significado a ser transmitido ao interlocutor. São utilizadas nas expressões de pedido pelos japoneses nas sete situações: 


\section{Quadro 4 - Modelo de conjuntos de funções enunciativas utilizados pelos locutores de acordo com o grau de cada situação}

\begin{tabular}{|c|l|}
\hline Situação & Conjunto de funções enunciativas \\
\hline-2 & A princípio não se usa [pedido], usa-se [ordem], [pergunta], [instrução] \\
\hline-1 & {$[$ pedido], [pergunta], [instrução] } \\
\hline 0 & {$[$ desculpa] $+[$ pedido], [pergunta] + possibilidade de [explicação] } \\
\hline+1 & {$[$ chamado], [desculpa] $+[$ explicação] $+[$ pedido], [pergunta] } \\
\hline+2 & $\begin{array}{l}{[\text { desculpa] }+[\text { indicação do conteúdo da fala], [verificação das circuns- }} \\
\text { tâncias] }+[\text { explicação] }+ \text { [pedido direto ou indireto], [pergunta] }\end{array}$ \\
\hline+3 & $\begin{array}{l}{[\text { desculpa] }+[\text { indicação do conteúdo da fala], [verificação das circunstâncias] }+} \\
{[\text { explicação] }+ \text { [pedido direto ou indireto], [pergunta] + [promessa] }+[\text { súplica] }}\end{array}$ \\
\hline+4 & A princípio não se realiza o ato \\
\hline
\end{tabular}

Para Kabaya (ibidem), conforme a o grau da situação aumenta, a "lógica" do interlocutor (enunciatário) de realizar o pedido para o locutor (enunciador) diminui, e por isso nas situações -2 e -1, onde o enunciador faz um pedido ao garçom, ou a mãe fala para o filho fazer a lição de casa, a lógica do interlocutor (enunciatário) de realizar o pedido é evidente, e então falas com as funções de [ordem], [pergunta] ou [instrução] são usadas ao invés de utilizar a função de [pedido]. Por essas razões, Kabaya (1993) diz que a partir da situação 0 é que podemos pensar em reais situações de pedido.

Da situação 0 em diante, o locutor elabora uma estratégia mais complexa para efetuar um pedido, utilizando falas com as funções de [chamado], [hesitação], [desculpa] no início da conversa, além de empregar funções como [indicação do conteúdo da fala], [verificação das circunstâncias] + [explicação] antes de usar o [pedido direto ou indireto], [pergunta]; também pode existir [promessa] + [súplica] no final da conversa. Segundo Goffman (1971), as pessoas, quando em uma conversa produzem (produziram ou produzirão) um ato que causa um prejuízo ao interlocutor, tentam reduzir ao mínimo o dano da relação entre os participantes, para sua imagem não tornar negativa com o interlocutor. Para tanto, os locutores, ao executar um pedido, utilizam diversas falas com funções diferentes do [pedido] para restaurar ou restabelecer a conversa, tentando não danificar sua imagem para com o interlocutor.

Há uma variação no uso das funções enunciativas de acordo com o grau da situação, e segundo Kabaya (1993) o locutor pode deslocar o seu ato de fala para 1 grau maior ou menor com a situação, que está presenciando, por existir diferença pessoal entre pessoas de uma mesma sociedade, para obter sucesso no uso de uma estratégia linguística. Mas se o conjunto de funções enunciativas não corresponder ao grau determinado para a situação (de acordo com o nível do conteúdo e do interlocutor da situação) em mais de 2 
níveis, o ato pode ser considerado "sem educação" ou afetado, por ser "polido demais", como pode ser observado no exemplo abaixo.

Em uma situação de grau 0 (pedir para o funcionário de uma estação de trem verificar um objeto perdido $=$ nível do interlocutor 0 , nível do conteúdo 0 ), o conjunto deve ser de [desculpa] e [pedido ou pergunta] + opção do uso de [pedido] (sumimasen, eki ni kasa o okiwasuretandesu kedo, dareka ga todoketekuremasendeshitaka "Por favor, eu esqueci o meu guarda-chuva na estação, será que alguém entregou aqui?"). Neste caso, segundo Kabaya, se o locutor utilizar o conjunto de funções enunciativas do grau -1 ou +1 , não haverá problemas, porém, se forem utilizados conjuntos de grau com -2 ou +2 , pode parecer sem educação ou polido demais: no grau -2 , usa-se [ordem] (watashi no kasa o sagashite "procura meu guarda-chuva"), [pergunta] (watashi no kasa, arimasuka? "tem meu guarda-chuva?") ou [instrução] (watashi no kasa o sagashinasai "procure meu guarda-chuva"); no grau +2 , o conjunto é formado por [desculpa] (sumimasen "desculpa") + [indicação do conteúdo da fala] (onegai ga arimasuga "tenho um pedido"), [verificação das circunstâncias] (ima ojikan yoroshii deshôka "teria um minuto agora?") + [explicação] (ekini kasa o okiwasuretandesuga "é que esqueci o meu guarda-chuva na estação") + [pedido direto ou indireto] ou [pergunta] (dareka ga watashi no kasa o todokete kudasaranakattadeshôka "será que alguém não teria entregado aqui?"), neste ato, deixando-o mais polido do que o necessário não ficaria irônico, porém falta objetividade pelo uso excessivo de funções enunciativas. $\mathrm{O}$ uso de excesso de funções enunciativas pode soar irônico, como por exemplo no seguinte caso, em que a mãe tinha pedido para o filho (nível do interlocutor -1) arrumar o seu quarto alguns dias atrás, porém ele ainda não o fez, e está pedindo novamente (nível do conteúdo -1), e nesta situação, o grau seria -2 , usando o conjunto [desculpa] (isogashii noni gomenne "desculpa, viu, se está ocupado") + [pedido], [pergunta] (demo heya o katazuketekuremasenka "mas será que não poderia arrumar o quarto?") + possibilidade de [explicação] (sukoshi chirakatte irumitaina node "é que parece estar um pouco desarrumado"). Já o conjunto para situações com grau 0 , este ato ficaria meio irônico, uma vez que, de acordo com o modelo apresentado por Kabaya, o normal seria uso de [ordem] (hayaku heya o katazuketene "arrume logo o quarto, viu?"), [pergunta] (kyôjû ni katazukeru? "arruma ainda hoje?") ou [instrução] (heya o katazukenasai "arrume o quarto").

\section{METODOLOGIA DA PESQUISA}

A metodologia adotada na pesquisa é de caráter qualitativo, de base interpretativa e com respaldo no método quantitativo dos tipos de funções presentes nos pedidos realizados pelos nisseis.

Para realizar a análise dos dados, foi utilizada a unidade move que, segundo Tsuda (1989) e Nakata (1995) as quais se baseiam em Coulthard(1977), pode ser usada em uma análise de discurso para verificar o tipo e o número de funções enunciativas que há em 
um ato de fala, como a menor unidade funcional de um discurso. Por exemplo, no caso da seguinte fala:

\section{Quadro 5- Amostra de uma fala dividida em moves}

\begin{tabular}{|c|c|c|}
\hline [pedido de desculpa] & [explicação/justificativa] & [pedido] \\
\hline Desculpa, & mas surgiu um compromisso. & $\begin{array}{c}\text { Você poderia trocar o seu } \\
\text { dia de folga comigo? }\end{array}$ \\
\hline
\end{tabular}

A fala acima pode ser dividida em três partes, de acordo com a função que cada unidade exerce. Neste caso, "Desculpa" tem a função de pedir desculpas: [pedido de desculpa], "mas surgiu um compromisso" tem a função de explicar uma situação: [explicação/justificativa], e "Você poderia trocar o seu dia de folga comigo?" tem a função de pedir algo: [pedido].

O instrumento utilizado para obtenção de dados foram as respostas do questionário, em que os informantes escreveram como utilizam diversos tipos de move, que variaram de acordo com o cenário, o papel social dos participantes e o contexto de cada situação. A coleta de dados foi realizada no estado de São Paulo, em associações de nikkei (kaikan), nas quais as pessoas se reúnem para praticarem atividades ligadas à cultura japonesa, cantando músicas, dançando odori (danças japonesas) e ensinando a língua japonesa, além de realizarem eventos associados à colônia, tais como concursos de karaokê e torneios de beisebol e softball. O grupo de informantes são nisseis homens e mulheres entre 40 e 69 anos bilíngues (falantes da língua japonesa e portuguesa), formado por 96 pessoas, que foi dividido conforme idade e sexo, como mostra a tabela abaixo:

Quadro 6 - Distribuição do número de informantes por sexo e idade

\begin{tabular}{|c|c|c|c|}
\hline Nisseis & Homem & Mulher & Total \\
\hline 40 a 49 & 10 & 18 & 28 \\
\hline 50 a 59 & 19 & 16 & 35 \\
\hline 60 a 69 & 18 & 15 & 33 \\
\hline Total & 47 & 49 & 96 \\
\hline
\end{tabular}

\section{ANÁLISE DOS DADOS}

Nesta seção, apresentamos para análise os dados das expressões de pedido faladas em japonês pelos nisseis do Brasil, divididos em move. 


\subsection{Apresentação das funções dos diversos tipos de move}

Antes de entrarmos na análise das funções de moves utilizados pelos informantes em cada situação, explicamos no quadro 7 todos os tipos de formas funcionais encontradas em nossos dados.

\section{Quadro 7 - Tipos de move utilizados pelos informantes}

\begin{tabular}{|c|c|c|c|}
\hline \multirow{2}{*}{ tipos de move } & \multirow{2}{*}{ explicação } & \multicolumn{2}{|c|}{ exemplos } \\
\hline & & japonês & tradução \\
\hline [Saudação] & $\begin{array}{l}\text { atos de fala em que o locutor } \\
\text { cumprimenta o interlocutor }\end{array}$ & Konnichiwa & Boa tarde \\
\hline [Chamado] & $\begin{array}{l}\text { atos de fala utilizados pelo locutor a } \\
\text { fim de atrair a atenção do interlocutor, } \\
\text { e também demonstrar respeito }\end{array}$ & $\begin{array}{l}\text { (1) nome + chan } \\
\text { (2) nome }+ \text { san } \\
\text { (3) sensei }\end{array}$ & $\begin{array}{l}\text { (1) Forma de } \\
\text { tratamento, que } \\
\text { demonstra carinho } \\
\text { ou intimidade } \\
\text { (2) Forma de } \\
\text { tratamento, que } \\
\text { demonstra respeito } \\
\text { (3) professor }\end{array}$ \\
\hline [Hesitação] & $\begin{array}{l}\text { atos de fala que mostram } \\
\text { postura cerimoniosa }\end{array}$ & $\begin{array}{l}\text { (1) Ano sa } \\
\text { (2) Ano }\end{array}$ & $\begin{array}{l}\text { (1) Então } \\
\text { (2) Bem... }\end{array}$ \\
\hline [Desculpa] & $\begin{array}{l}\text { expressões usadas com o } \\
\text { intuito de pedir perdão }\end{array}$ & $\begin{array}{l}\text { (1) Moushi wakenai } \\
\text { (2) Gomen } \\
\text { (3) Sumimasen }\end{array}$ & $\begin{array}{l}\text { (1) Não tenho } \\
\text { desculpas } \\
\text { (2) Perdão } \\
\text { (3) Desculpe-me }\end{array}$ \\
\hline $\begin{array}{l}\text { [Indicação } \\
\text { do conteúdo } \\
\text { da fala] }\end{array}$ & $\begin{array}{l}\text { expressões que indicam o } \\
\text { conteúdo da conversa antes de } \\
\text { se entrar no assunto principal }\end{array}$ & $\begin{array}{l}\text { Onegai ga arun } \\
\text { dakedo }\end{array}$ & $\begin{array}{l}\text { Eu tenho um favor } \\
\text { para te pedir, mas... }\end{array}$ \\
\hline $\begin{array}{l}\text { [Verificação } \\
\text { das } \\
\text { circunstâncias] }\end{array}$ & $\begin{array}{l}\text { expressões utilizadas para verificar } \\
\text { se o ouvinte possui tempo ou } \\
\text { condição de atender o locutor }\end{array}$ & Chotto ii desuka? & Teria um tempinho? \\
\hline $\begin{array}{l}\text { [Fornecimento } \\
\text { de } \\
\text { informações } \\
\text { pessoais] }\end{array}$ & $\begin{array}{l}\text { expressões utilizadas com o } \\
\text { intuito de tranquilizar o ouvinte. } \\
\text { Nesse caso, o locutor fornece suas } \\
\text { informações pessoais ao ouvinte }\end{array}$ & $\begin{array}{l}\text { Kinjo ni sundeiru } \\
\text {... desu }\end{array}$ & $\begin{array}{l}\text { Meu nome é..., } \\
\text { sua vizinha }\end{array}$ \\
\hline [Explicação] & $\begin{array}{l}\text { expressões que explicam o motivo e a } \\
\text { situação que o locutor está enfrentando }\end{array}$ & $\begin{array}{l}\text { Kazoku ga } \\
\text { taoretanode... }\end{array}$ & $\begin{array}{l}\text { Alguém da } \\
\text { família está mal }\end{array}$ \\
\hline [Condição] & $\begin{array}{l}\text { realce na realização do ato apenas } \\
\text { no caso de o interlocutor tiver a } \\
\text { disponibilidade de realizá-lo }\end{array}$ & Moshi kanô dattara & Se for possível \\
\hline [Pedido] & $\begin{array}{l}\text { atos de pedido realizados de forma } \\
\text { direta, com o acréscimo de um } \\
\text { verbo auxiliar ao verbo principal, } \\
\text { de modo a obter o modelo típico } \\
\text { de atos de pedidos diretos }\end{array}$ & $\begin{array}{l}\text { (1) Tottekureru } \\
\text { (2) Kite } \\
\text { itadakemasenka }\end{array}$ & $\begin{array}{l}\text { (1) Pode pegar } \\
\text { para mim? } \\
\text { (2) Poderia vir } \\
\text { comigo? }\end{array}$ \\
\hline
\end{tabular}




\begin{tabular}{|c|c|c|c|}
\hline \multirow{2}{*}{ tipos de move } & \multirow{2}{*}{ explicação } & \multicolumn{2}{|c|}{ exemplos } \\
\hline & & japonês & tradução \\
\hline [Ordem] & $\begin{array}{l}\text { atos de pedidos que expressam } \\
\text { significado de ordem }\end{array}$ & Totte & Pegue \\
\hline [Desejo] & $\begin{array}{l}\text { nestes atos, o desejo do locutor } \\
\text { é transmitido ao ouvinte }\end{array}$ & Tottehoshii & $\begin{array}{l}\text { Quero que } \\
\text { você pegue }\end{array}$ \\
\hline $\begin{array}{l}{[\text { Desejo }+} \\
\text { Mitigador }]\end{array}$ & $\begin{array}{l}\text { enunciados que cumprem o requisito } \\
\text { de integridade com relação ao locutor, } \\
\text { que requer a realização de algum ato } \\
\text { pelo interlocutor em seu benefício. } \\
\text { Mas, para isso ser considerado um tipo } \\
\text { de pedido indireto, é fundamental a } \\
\text { presença do mitigador ou atenuador } \\
\text { kedo ou ga (mas), que expressam o } \\
\text { sentido de oposição no fim da frase. } \\
\text { Sem a presença desse mitigador, } \\
\text { o enunciado torna-se simples ato } \\
\text { de desejo (Kumatoridani,1995) }\end{array}$ & $\begin{array}{l}\text { (1) Tottehoshiikedo } \\
\text { (2) Kite itadakitai } \\
\text { desu ga }\end{array}$ & $\begin{array}{l}\text { (1) Gostaria de que } \\
\text { pegasse, mas... } \\
\text { (2) Eu gostaria que } \\
\text { viesse, mas... }\end{array}$ \\
\hline [Permissão] & $\begin{array}{l}\text { atos por meio dos quais o locutor tenta } \\
\text { adquirir permissão do interlocutor } \\
\text { para realizar algo. Em japonês, } \\
\text { conforme a explicação de Kabaya } \\
\text { (2007), os japoneses utilizam esse tipo } \\
\text { de expressão para fazer um pedido, } \\
\text { uma vez que tem a característica } \\
\text { de desviar a ação do ato de pedido } \\
\text { do interlocutor para o locutor, } \\
\text { aumentando consequentemente o } \\
\text { nível de polidez da expressão }\end{array}$ & $\begin{array}{l}\text { Kite morattemo } \\
\text { ii desuka }\end{array}$ & $\begin{array}{l}\text { Posso pedir o } \\
\text { favor de vir? }\end{array}$ \\
\hline [Súplica] & $\begin{array}{l}\text { atos em que o locutor faz uma } \\
\text { súplica veemente para que } \\
\text { o pedido seja realizado }\end{array}$ & $\begin{array}{l}\text { (1) Onegaishimasu } \\
\text { (2) Tanomu }\end{array}$ & $\begin{array}{l}\text { (1) "Por favor } \\
\text { (2) Eu imploro }\end{array}$ \\
\hline $\begin{array}{l}\text { [Requerimento } \\
\text { de } \\
\text { consentimento] }\end{array}$ & $\begin{array}{l}\text { atos do locutor que visam requerer o } \\
\text { consentimento do interlocutor com } \\
\text { relação ao pedido a ser atendido }\end{array}$ & $\begin{array}{l}\text { (1) Ii? } \\
\text { (2) Dekiru? }\end{array}$ & $\begin{array}{l}\text { (1) Tudo bem? } \\
\text { (2) Você pode? }\end{array}$ \\
\hline [Gratidão] & $\begin{array}{l}\text { formas de mostrar gratidão ao ouvinte, } \\
\text { caso o interlocutor realize o ato pedido }\end{array}$ & Arigatô gozaimasu & Muito obrigado \\
\hline
\end{tabular}

Esses foram os tipos de move que apareceram nos dados dos nisseis, nas duas situações de pedidos que foram analisadas neste presente trabalho.

\subsection{Resultados da análise}

Na situação 1, em que o informante precisa pedir para um familiar mais novo (filho, irmão mais novo) passar o saleiro em uma mesa na hora da refeição, o grau de ônus é -2 e, para Kabaya (1993), a estratégia adotada nesse tipo de situação é a da utilização de 
[ordem], [pergunta] ou [instrução]. A princípio, atos de fala com a função de [pedido] não são usados no modelo de Kabaya.

Os modelos de estratégias utilizados pelos informantes da nossa pesquisa foram:

\section{Tabela 1 - Modelos de estratégia utilizados na situação 1}

\begin{tabular}{|l|c|c|}
\hline [pedido] & 44 & $47,3 \%$ \\
\hline [ordem] & 19 & $20,4 \%$ \\
\hline [chamado] + [pedido] & 13 & $14,0 \%$ \\
\hline [chamado] + [ordem] & 4 & $4,3 \%$ \\
\hline [súplica] + [pedido] & 3 & $3,2 \%$ \\
\hline [súplica] + [ordem] & 3 & $3,2 \%$ \\
\hline [chamado] & 1 & $1,1 \%$ \\
\hline [desculpa] + [ordem] & 1 & $1,1 \%$ \\
\hline [chamado] + [pedido] + [gratidão] & 1 & $1,1 \%$ \\
\hline [súplica] & 1 & $1,1 \%$ \\
\hline [hesitação] + [pedido] & 1 & $1,1 \%$ \\
\hline [desculpa] + [pedido] & 1 & $1,1 \%$ \\
\hline [chamado] + [pedido] + & 93 & $1,1 \%$ \\
\hline [súplica] + [gratidão] & & $100 \%$ \\
\hline TOTAL & 1 & \\
\hline
\end{tabular}

A estratégia mais utilizada pelos informantes nisseis nessa situação foi de [pedido], sem nenhum outro move junto, por parte de $47 \%$ dos informantes, e a segunda mais utilizada é de [ordem], com $20 \%$, o que mostra que a maioria dos informantes não utilizou a estratégia mais adequada. Se somarmos os $20 \%$ dos informantes que usaram [ordem] com os $4 \%$ que utilizaram [chamado] + [ordem], chegamos à conclusão de que apenas $24 \%$ dos informantes utilizaram estratégias apropriadas à situação. Em contrapartida, $62 \%$ dos informantes utilizaram estratégias com [pedido] sem moves com funções restauradoras e nenhum informante fez uso da estratégia [pergunta] ou [instrução], que fazem parte do modelo de Kabaya. Os demais informantes, 14\%, apresentaram estratégias com moves restauradores, que não são apropriadas a essa situação.

Em todo o caso, embora não sendo as mais adequadas, podemos considerar o uso de pedido como estratégia aceitável à situação, uma vez que, conforme apresentado no modelo de conjuntos de move em relação ao grau de cada situação de Kabaya, se 
o deslocamento do (conjunto de) move usado com o grau da situação for de apenas 1 grau, este ato de fala pode ser considerado satisfatório, porque o uso apenas do [pedido] corresponde a situações de grau -1. Entretanto, podemos avaliar também que, embora os japoneses do Japão façam uso da estratégia de ordem, levando em conta a relação hierárquica entre falante e o interlocutor, os nossos informantes falam de forma mais atenciosa para conseguirem que o outro faça o que querem que seja realizado. Ou seja, os falantes nisseis não levam em conta a diferença hierárquica entre si e o interlocutor mais jovem, o que motiva a opção pela estratégia de "pedido" em vez de "ordem".

Na situação 2, o informante precisa ir até a casa de um médico, que mora na vizinhança, pedir para ir a sua casa, quando alguém da sua família está passando mal, nesta situação o grau de ônus é +3. O modelo de conjuntos de move apresentado por Kabaya (1993) para esse tipo de situação é formado por pelo menos quatro ou cinco tipos, compostos de: [chamado], [desculpa] ou [hesitação] + [indicação do conteúdo da fala] ou [verificação das circunstâncias] + [explicação] + [pedido], [desejo + mitigador], [permissão] ou [pergunta] + [promessa], [contribuição] ou [súplica].

As estratégias utilizadas pelos informantes do nosso estudo foram:

Tabela 2 - Modelos de estratégia utilizados na situação 2

\begin{tabular}{|l|c|c|}
\hline [explicação] + [pedido] & 13 & $15,5 \%$ \\
\hline [chamado] + [desculpa] + [explicação] + [pedido] & 12 & $14,3 \%$ \\
\hline [desculpa] + [explicação] + [pedido] & 8 & $9,5 \%$ \\
\hline [chamado] + [explicação] + [pedido] + [súplica] & 5 & $8,3 \%$ \\
\hline [chamado] + [pedido] & 5 & $6,0 \%$ \\
\hline [chamado] + [explicação] + [pedido] & 4 & $6,0 \%$ \\
\hline $\begin{array}{l}\text { [chamado] +[ desculpa] + [explica- } \\
\text { ção] + [pedido] + [súplica] }\end{array}$ & 3 & $4,8 \%$ \\
\hline [desculpa] + [pedido] & 4 & $3,6 \%$ \\
\hline [desculpa] + [explicação] + [pedido] + [súplica] & 2 & $3,6 \%$ \\
\hline [chamado] + [desculpa] + [pedido] & 2 & $2,4 \%$ \\
\hline [desculpa] + [pedido]+ [súplica] & 2 & $2,4 \%$ \\
\hline [pedido] & 2 & $2,4 \%$ \\
\hline [saudação] + [desculpa] + [explicação] + [pedido] & $2,4 \%$ \\
\hline
\end{tabular}




\begin{tabular}{|c|c|c|}
\hline$[$ chamado $]+[$ desculpa $]+[$ pergunta $]$ & 1 & $1,2 \%$ \\
\hline [desculpa] + [explicação] + [condição] + [pedido] & 1 & $1,2 \%$ \\
\hline [saudação] $+[$ desculpa $]+[$ explicação] + [pergunta $]$ & 1 & $1,2 \%$ \\
\hline [chamado] + [súplica $]+[$ explicação $]$ & 1 & $1,2 \%$ \\
\hline [súplica] + [desejo] & 1 & $1,2 \%$ \\
\hline [súplica $]+[$ explicação $]+[$ pedido $]$ & 2 & $1,2 \%$ \\
\hline [pedido $]+[$ explicação $]+[$ desejo+mitigador $]+[$ súplica $]$ & 1 & $1,2 \%$ \\
\hline [chamado] + [explicação] & 1 & $1,2 \%$ \\
\hline [desculpa $]+[$ explicação] $+[$ ordem $]$ & 1 & $1,2 \%$ \\
\hline $\begin{array}{l}\text { [saudação }]+[\text { desculpa }]+[\text { explicação }]+ \\
{[\text { chamado }]+[\text { pedido }]+[\text { súplica }]}\end{array}$ & 1 & $1,2 \%$ \\
\hline $\begin{array}{l}\text { [desculpa] }+[\text { explicação] }+ \text { [persua- } \\
\text { são }]+[\text { pedido }]+[\text { súplica }]\end{array}$ & 1 & $1,2 \%$ \\
\hline $\begin{array}{l}\text { [desculpa] + [apresentação] }+ \text { [expli- } \\
\text { cação] }+ \text { [pedido] }+ \text { [súplica }]\end{array}$ & 1 & $1,2 \%$ \\
\hline$[$ chamado $]+[$ pedido $]+[$ súplica $]$ & 1 & $1,2 \%$ \\
\hline [desculpa] $+[$ explicação] + [permissão] & 1 & $1,2 \%$ \\
\hline$[$ chamado $]+[$ desculpa $]+[$ permissão $]$ & 1 & $1,2 \%$ \\
\hline [explicação] + [verificação $]+$ [pedido $]+[$ súplica $]$ & 1 & $1,2 \%$ \\
\hline TOTAL & 84 & $100,0 \%$ \\
\hline
\end{tabular}

A característica marcante das respostas a essa situação é de que não há a predominância de uma estratégia nos dados dos informantes, diferentemente da situação analisada anteriormente. Por essa razão, a soma das três estratégias mais utilizadas não ultrapassa $50 \%$ do total dos dados. Os conjuntos de move mais utilizados foram:

- [explicação] + [pedido], seguido por

- [chamado $]+[$ desculpa $]+[$ explicação $]+[$ pedido $]$ e

- [desculpa $]+[$ explicação] + [pedido],

com 15,5\%, 14,3\% e 9,5\% de ocorrências, respectivamente. Isso ocorre devido à grande diversidade no uso dos tipos de move, que aumenta conforme o grau de ônus de cada situação, motivando os informantes a utilizarem estratégias diversificadas. 
Examinando detidamente os tipos de moves usados pelos informantes, constatamos que apenas $7 \%$ dos informantes adotaram estratégias com quatro ou mais moves restaurativos, que são necessários para a execução desse tipo de situação. A maioria utilizou apenas três tipos de move restaurativos, que somam 35\%. Em seguida, apareceram informantes que utilizaram um ou dois tipos de move restaurativos, com $28 \%$ cada, e os informantes que utilizaram somente [pedido] foram $2 \%$ do total. Como conclusão, podemos afirmar que os conjuntos de moves usados pelos informantes não podem ser considerados satisfatórios, de acordo com o modelo de Kabaya (1993).

Em outras palavras, observamos na situação 2 que os informantes tendem a usar menos unidades de estratégia da fala e sem teor restaurativo do que o que preza o modelo de Kabaya para atenuar o ônus que o pedido pode causar ao interlocutor. A forma mais direta de pedido e a simplificação nas estratégias podem ser a prova de que entre o grupo dos falantes nipo-brasileiros, pelo menos restritos ao universo dos informantes que contribuíram para a nossa pesquisa, a questão do ônus não é considerada tão grande como no Japão, havendo entre os falantes de japonês na comunidade nipo-brasileira do Brasil uma percepção de maior proximidade e familiaridade por serem falantes que compartilham o uso da mesma língua de minoria na sociedade em que domina a língua portuguesa.

\section{CONSIDERAÇÕES FINAIS}

Neste trabalho, foram observados os tipos de estratégias utilizadas pelos nisseis residentes no Brasil quando realizam pedidos em língua japonesa, centrando-se em duas possíveis situações, com diferença no grau de ônus. E os resultados de nossa pesquisa mostraram que os informantes usam estratégias aceitáveis para pedidos simples, mas não exatamente apropriadas; e para pedidos complexos, fazem uso de estratégias não satisfatórias, tendo sempre como parâmetro o modelo apresentado por Kabaya.

A pergunta que nos ocorre é: usam-se menos combinações de moves e ainda sem os elementos restaurativos em pedidos complexos por não acharem necessário fazê-lo? Ou por falta de habilidade linguística? Caso for pelo problema de habilidade na fala, isso tem causado algum atrito com o(s) interlocutor(es)? Naturalmente, responder a essas perguntas requer outra pesquisa que inclua perguntas aos informantes sobre o que acham de suas formas de expressões de pedido, mas nem sempre os falantes têm consciência do motivo por que falam da forma como falam. Somos da opinião de que as escolhas de estratégias da parte dos nossos informantes nisseis da comunidade nipo-brasileira no Brasil, mesmo sendo intuitivas, mostram que a percepção com relação ao contexto e ao interlocutor é diferente da dos falantes de língua japonesa no Japão. E que por conseguinte, as estratégias usadas pelos informantes podem não coincidir com as comumente usadas pelos falantes do Japão. Assim sendo, torna-se importante que os falantes se conscientizem que, ao estabelecer comunicação com os interlocutores japoneses no Japão, as estratégias utilizadas normalmente no Brasil devem ser revistas, uma vez que no Japão, os falantes de língua japonesa prezam fatores como hierarquia social 
entre os falantes, além de terem a consciência de uma maior preocupação para desfazer o ônus que um pedido pode causar ao interlocutor. São fatores que refletem diretamente nas formas da fala, assim como as formas da fala escolhidas pelos informantes nisseis do Brasil, que carregam por sua vez seus respectivos princípios.

\section{REFERÊNCIAS BIBLIOGRÁFICAS}

AUSTIN, John Langshaw. How to Do Things with Words. Cambridge: Harvard University Press, 1962.

COULTHARD, Malcolm. An Introduction to Discourse Analysis. London: Longman, 1977.

FOUCAULT, Michel. L'archéologie du Savoir. Paris: Gallimard. 1969. (tradução japonesa por Yujiro Nakamura: Chino kôkogaku. Tóquio: Kawade Shobo, 1981).

GOFFMAN, Erving. Relations in Public. London: Penguin, 1971.

KABAYA, Hiroshi. Teineisa no genri ni motozuku kyoka motome gata hyôgen ni kansuru kôsatsu (Reflexão sobre as expressões para pedido de permissão de acordo com o princípio da polidez). Kokugo kenkyû to shiryô (Pesquisas e dados da língua japonesa), Tóquio: Kokugo kenkyû to shiryô no kai, vol. 30, p. 37-46, 2007.

KABAYA, Hiroshi; KAWAGUCHI, Yoshikazu; SAKAMOTO, Megumi. Irai hyôgen hôryaku no bunseki to kijutsu: taigû hyôgen kyôiku heno ôyô ni mukete (Descrição e análise das estratégias das expressões de pedido: voltada para aplicação na educação da cortesia verbal). Waseda daigaku nihongo kenkyû kyôiku sentâ kiyô (Anais do Centro de Ensino e Pesquisa de Língua Japonesa de Waseda University). Tóquio: Waseda Daigaku, vol.5, p. 52-69, 1993.

KUMATORIDANI, Tetsuo. Hatsuwa Kôi Riron kara Mita Irai Hyôgen: Hatsuwa Kôi kara Danwa Riron e (A visão das expressões de pedido a partir da tória dos atos de fala: dos atos de fala para as teorias sobre discurso). Nihongogaku (Estudos de Língua Japonesa), Tóquio: Meiji Shoin, Vol.14-10, p.12-21, 1995.

NAKATA, Tomoko. Hatsuwa no Tokuchô Kijutsu ni Tsuite: Tan'i toshite no "move" to bunseki no kanten (Descrição sobre as características do discurso: "move" como unidade e o ponto de vista analítico). Nihongogaku (Estudos de Língua Japonesa), Tóquio: Meiji Shoin, Vol.14-10, p.112-118, 1995.

NAKATO, Yasue. Burajiru nikkei imin shakai ni okeru "koroniago" no ichi (A posição da "língua da colônia" na sociedade dos imigrantes japoneses do Brasil". In: Okayama daigaku bungakubu Kiyô (Anais do Departamento de Letras de Okayama University) vol.70, p. 53-70, 2018.

SEARLE, John R. Os actos de fala - um ensaio de filosofia da linguagem. (Speech acts - an essay the philosophy of language). Trad. Carlos Vogt. Coimbra: Coimbra Livraria Almedina,1981.

TSUDA, Aoi. Shakai gengo gaku (Sociolinguística). Eigogaku taikei - Vol.6, Eigogaku no kanren bunya (Áreas conexas de Estudos da Língua Inglesa). Tóquio: Taishûkan Shoten, p. 416-420, 1989. 